Jurnal

Kardiologi Indonesia

J Kardiol Indones. 2013;34:I72-8

ISSN 0I 26/3773

Case Report

\title{
Symptomatic Myocardial Bridging Treated by Coronary Stenting
}

\author{
Johan Winata, Eben Reppi, Bambang Budiono, Reggy Lefrandt
}

Department of Cardiology, University of Sam Ratulangi / Heart \& Vascular Center Awal Bros Hospital Makassar, Indonesia
Background : Myocardial bridging is a congenital coronary anomaly with mostly benign course throughout life. However, several pathological clinical manifestations may accompany myocardial bridging, such as arrhythmia, angina, depressed left ventricular function, myocardial stunning, myocardial infarction, and sudden death. Symptomatic management with anti anginal agents should be adequate in most cases. Stenting, surgical resection of the bridge (myotomy), and coronary bypass surgery are only reserved for the rare patient with severe symptoms.

Case Report : A 44 year old man was admitted to the hospital because of the recurrent episodes of palpitations, syncope and chest pain. ECG showed sinus rhythm with bigeminy ventricular extra systoles. Echocardiography showed no regional wall motion abnormalities with normal ejection fraction. Coronary angiography showed myocardial bridging in mid LAD with no associated atherosclerotic coronary disease.

Recurrent episodes of angina and non-sustained VT were detected during observation in ICCU, despite anti-arrhytmic drug treatment and Kalium correction. Decision was made to perform $\mathrm{PCl}$ to cover bridging segment using drug eluting stent (DES). Post stent angiography showed no subsequent milking effect of systole with improvement in the occurrence of arrhythmia. Holter monitoring which was done I week after PCl showed no ventricular extrasystole found. Clinical evaluation and treadmill test at 3 months after the procedure demonstrated good clinical condition and the patient remained free of symptoms.

Conclusion : A successful coronary stenting to mid LAD due to myocardial bridging with persistent symptoms despite medial therapy. A thorough follow up should be done to identify the possibility of luminal narrowing caused by intimal proliferation or stent fracture due to external compression.

(J Kardiol Indones. 20। 3;34:I 72-8)

Keywords: myocardial bridging, stenting 
Jurnal

\title{
Pemasangan Stent pada Pasien dengan Myocardial Bridging Simtomatik
}

\author{
Johan Winata, Eben Reppi, Bambang Budiono, Reggy Lefrandt
}

\begin{abstract}
Latar belakang : Myocardial bridging (MB) adalah kelainan kongenital degnan perjalanan penyakit yang jinak pada sebagian besar kasus. Namun, beberpaa manifestasi klinis patologis dapat menyertai MB, diantaranya adalah aritmia, angina, penurunan fungsi ventrikel kiri, myocardial stunning, infark miokard, dan kematian mendadak. Penanganan simtomatik dengan obat anti angina memberikan efek yang baik pada kebanyakan kasus. Stenting, operasi reseksi otot MB (miotomi), dan bedah pintas coroner (coronary artery bypass surgery/CABG) hanya dilakaukan untuk kaus tertentu dengan gejala yang berat dan refrakter terhadap medikamentosa.

Case Report : Seorang pria 44 tahun masuk rumah sakit dengan keluhan palpitasi, nyeri dada, dan sinkop berulang. EKG menunjukkan irama sinus dengan ekstrasistole ventrikel bigemini. Ekokardiografi menunjukkan hasil yang normal, angiografi koroner menunjukkan adanya MB pada mid-LAD tanpa adanya atherosklerosis. Terdapat episode takikardia ventrikel selama observasi di ruang rawat intensif jantung dengan pemberian amiodarone intravena.

Intervensi koroner perkutan (percutaneous coronary intervention/PCI) dilakuan 2 hari setelah angiografi koroner dengan menggunakan drug eluting stent (DES) sepanjang segmen MB. Angiografi setelah pemasangan stent menunjukkan tidak didapatkan lagi milking effect pada fase sistol dan ekstrasistol ventrikel juga tidak lagi ditemukan. Holter monitoring yang dilakukan 1 minggu setelah PCI menunjukkan tidak ada ekstrasistol yang terekam. Evaluasi klinis dan tes treadmil setelah 3 bulan pemasangan stent menunjukkan hasil yang normal tanpa ada gejala sisa nyeri dada dengan kapasitas latihan yang baik.

Conclusion : Telah dilaporkan pemasangan stent koroner pada pasien dengan MB pada mid-LAD yang refrakter terhadap terapi medikamentosa, dengan hasil yang baik. Pemantauan berkala harus terus dilakukan untuk mengidentifikasi penyempitan lumen pembuluh darah yang disebabkan oleh proliferasi intima atau fraktur stent karena kompresi eksternal.
\end{abstract}

(J Kardiol Indones. 2013;34:172-8)

Kata kunci: myocardial bridging, stent

\section{Latar Belakang}

Myocardial bridging (MB) seringkali ditemukan pada pemeriksaan angiografi koroner diagnostik. ${ }^{1,2} \mathrm{MB}$

\footnotetext{
Alamat Korespondensi:

Dr. Johan Winata, SpJP. Departemen Kardiologi dan Kedokteran Vaskular Universitas Sam Ratulangi / Heart \& Vascular Center Rumah Sakit Awal Bros Makassar, Indonesia. E-mail: Winata.johan@ gmail.com
}

merupakan anomali kongenital, yang terjadi sebagai akibat tidak sempurnanya proses eksteriorasi dari jaringan arterial intratrabekular koroner primitif, dan umumnya terletak sepanjang segmen tengah (mid) dari arteri koronaria left anterior descending (LAD). ${ }^{2-5}$ Insiden MB dilaporkan bervariasi antara 15\%-85\% pada berbagai studi anatomis tetapi hanya ditemukan pada $0,5 \%$ to $16 \%$ pasien yang menjalankan angiografi koroner (coronary angiography/CA)..$^{3,6-8}$

Oleh karena perfusi arteri koronaria terutama 
terjadi pada saat fase diastolik, MB dipertimbangkan sebagai kondisi yang jinak, dan seringkali merupakan temuan yang kebetulan. ${ }^{9}$ Tetapi beberapa studi terkini menunjukkan adanya penurunan ringan aliran darah selama fase diastolik oleh karena kelambatan recoil dari pembuluh darah setelah kompresi otot jantung pada fase sistolik. ${ }^{7}$ Tetapi, beberapa gejala yang disebabkan oleh MB telah dilaporkan, seperti angina, aritmia, penurunan fungsi ventrikel kiri, stunning miokardium, dan kematian mendadak. ${ }^{7}$ Iskemia miokard yang disebabkan oleh kompresi sistolik dari segmen MB arteri koronaria lebih tampak pada keadaan hipertrofi ventrikel. ${ }^{1,10}$

Berdasarkan studi jangka panjang dari populasi dengan MB dari LAD menunjukkan prognosis yang baik, dan hanya sedikit laporan timbulnya infark miokard menetap yang dapat menyebabkan kematian, tidak ada terapi spesifik yang direkomendasikan., ${ }^{9}, 11,12$ Namun, untuk pasien dengan bukti klinis adanya iskemia, tatalaksana simptomatik dengan obat-obatan anti-angina yang adekuat perlu untuk diberikan pada kebanyakan kasus. 3,5,12 Pemasangan stent koroner, operasi reseksi MB (miotomi), ataupun bedah pintas koroner (coronary artery bypass surgery/CABG) hanya diperuntukkan bagi beberapa pasien dengan angina intractable, infark miokard rekuren, ataupun pada beberapa kasus dengan stenosis yang menetap pada segmen sebelum atau sepanjang MB. ${ }^{1,5,11,13}$ Hilangnya gejala akan segera tampak setelah dilakukannya miotomi atau CABG ${ }^{1}$. Beberapa literatur melaporkan komplikasi yang sangat jarang terjadi berupa aneurisma ventrikel kiri. ${ }^{14}$ Peranan pemasangan stent koroner masih kontroversial oleh karena tingginya angka instent restenosis dan stent fracture yang dapat terjadi setelah proses implantasi. ${ }^{1,15,16}$ Meskipun demikian, beberapa studi menunjukkan hasil yang memuaskan pada observasi jangka panjang. Komplikasi dan hasil jangka panjang dari modalitas terapi masih belum jelas karena belum adanya studi berskala besar yang telah dilakukan. Studi lebih lanjut jelas diperlukan untuk mendeskripsikan penggunaan berbagai modalitas terapi MB.

\section{Laporan Kasus}

Seorang pria 44 tahun masuk rumah sakit dengan keluhan palpitasi yang diikuti dengan sinkop dan nyeri dada berulang sejak 1 hari sebelum masuk rumah sakit. Pasien memiliki riwayat dirawat di rumah sakit kabupaten dengan sindroma koroner akut 2 bulan sebelumnya tanpa adanya bukti pemeriksaan EKG dan pemeriksaan enzim jantung dengan gejala nyeri dada saat bekerja berat terutama sejak 1 tahun terakhir. Pasien mengkonsumsi obat-obatan rutin baru selama 1 bulan terakhir, yaitu aspirin $160 \mathrm{mg}$, clopidogrel 75 $\mathrm{mg}$, candesartan $8 \mathrm{mg}$, dan simvastatin $20 \mathrm{mg}$. Pasien merupakan perokok dengan 1 bungkus rokok kretek setiap harinya. Riwayat tekanan darah tinggi, diabetes melitus, dislipidemia, dan riwayat keluarga yang menderita penyakit jantung disangkal oleh pasien. Pemeriksaan fisik menunjukkan tekanan darah 130/80 mmHg dengan detak jantung $88 \mathrm{x} /$ menit tidak regular. Pemeriksaan fisik lain dalam batas normal.

Pemeriksaan EKG pada saat masuk rumah sakit menunjukkan irama sinus dengan ekstrasistol ventrikel (ventricular extrasystole/VES) bigemini dan trigemini (gambar 1). Terdapat episode takikardia ventrikel (ventricular tachycardia/VT) non-sustained yang tidak terekam oleh EKG di ruang gawat darurat dan ruangan intensive cardiac care unit (ICCU). Evaluasi ekokardiografi tidak menunjukkan adanya abnormalitas gerakan regional dinding jantung dengan fraksi ejeksi yang normal. Tidak ditemukan pula adanya hipertrofi ventrikel kiri. Temuan lain menunjukkan nilai normal. CA menunjukkan MB pada mid-LAD

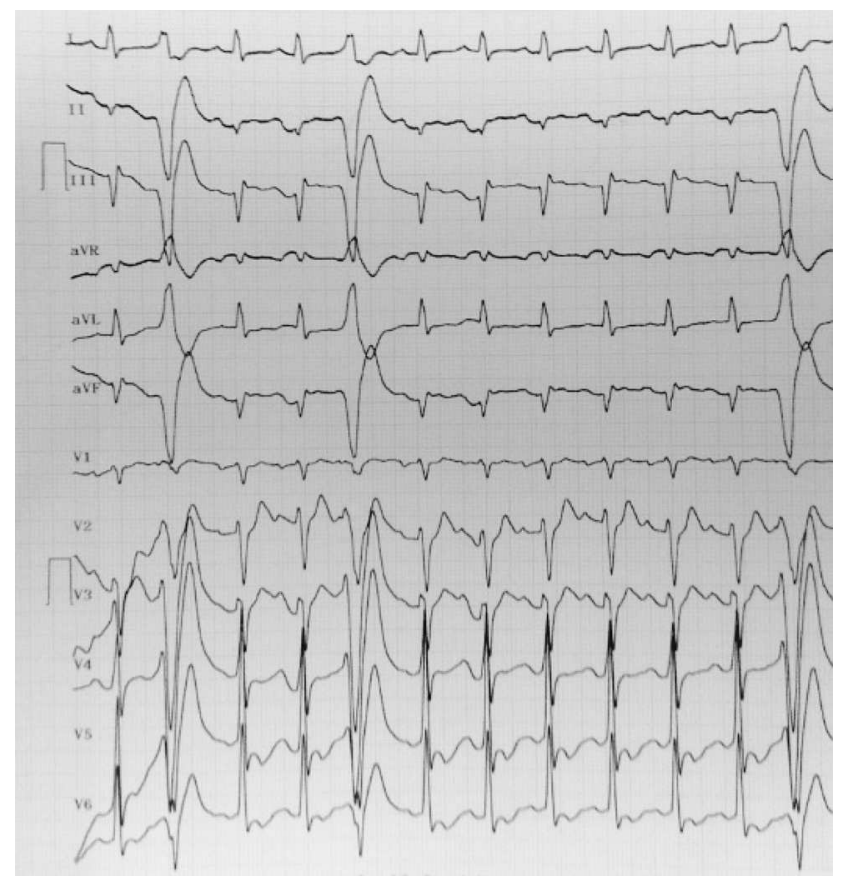

Gambar 1. EKG menunjukkan multipel VES pada saat masuk rumah sakit 

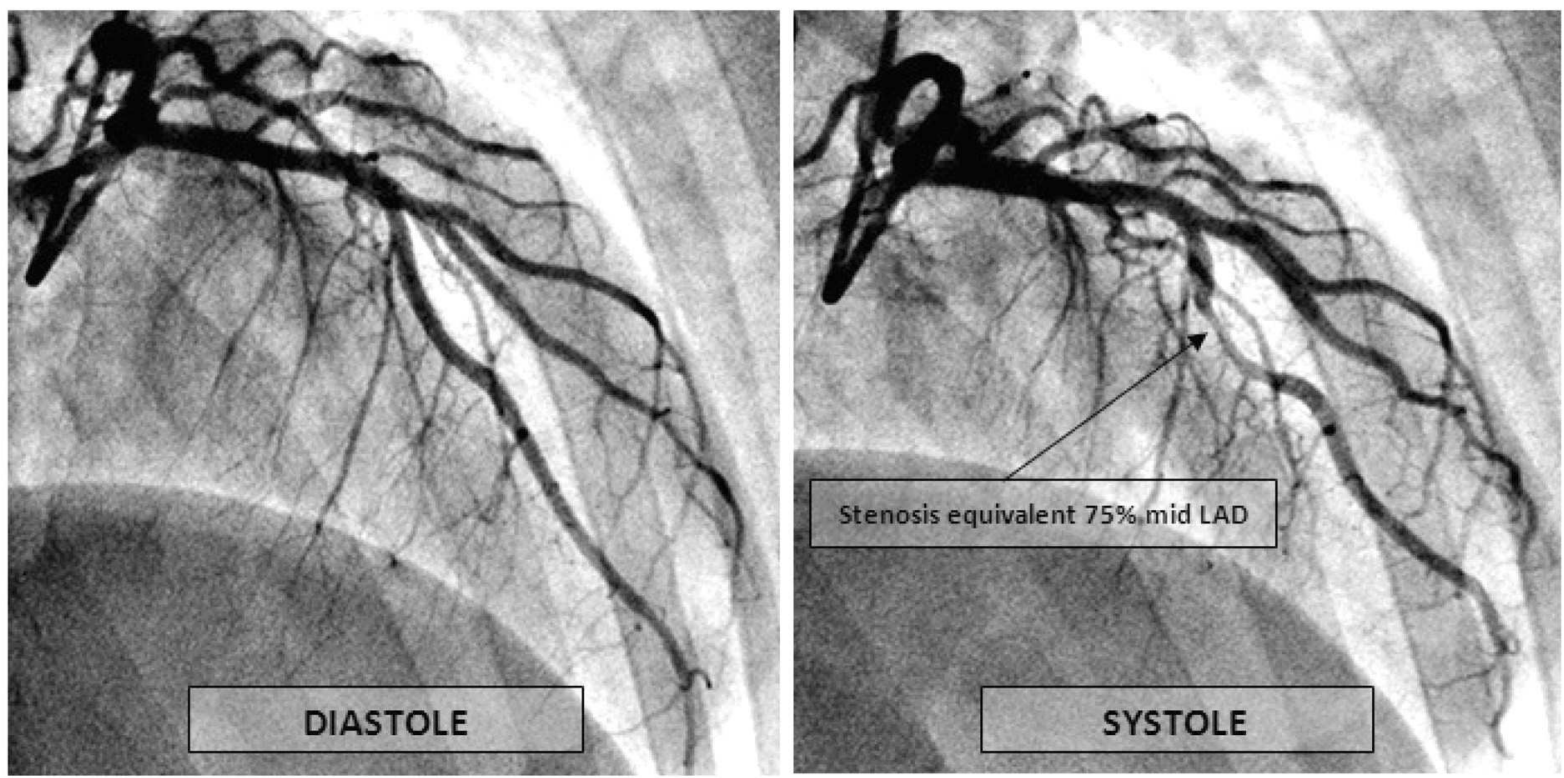

Gambar 2. Angiografi Koroner menunjukkan kompresi sistolik arteri koronaria pada mid-LAD, equivalen dengan stenosis $75 \%$.

tanpa adanya penyakit atherosklerosis koroner yang menyertai (gambar 2). Terapi yang diberikan adalah bisoprolol $5 \mathrm{mg}$ sekali sehari, loading dose Amiodarone $150 \mathrm{mg}$ intra-vena dalam 30 menit yang diikuti dengan $480 \mathrm{mg}$ dalam 6 jam dan selanjutnya $540 \mathrm{mg}$ dalam 18 jam. Preparat $\mathrm{KCl}$ intravena juga diberikan untuk mengatasi hipokalemia dengan target nilai Kalium 4 $\mathrm{mEq} / \mathrm{L}$.

Dengan terapi optimal, nyeri dada berulang yang diikuti dengan episode VT non-sustained berulang masih terjadi selama observasi di ruang ICCU. Intervensi koroner perkutan (percutaneous coronary intervention/PCI) dilakukan setelah 2 hari terapi medikamentosa. Sebuah drug-eluting stent (DES) 3.0 x $18 \mathrm{~mm}$ diimplantasi, dikembangkan pada tekanan 12 atm (nominal 8 atm), mencakup segemen MB. Unfractionated heparin 7000 unit diberikan intraarterial sebelum stent dikembangkan. Dua episode VT monofasik dengan gangguan kesadaran dan hemodinamik terekam selama prosedur PCI. Defibrilasi monofasik 100 Joule dilakukan sebanyak 2 kali dan berhasil mengkonversi VT kembali ke irama sinus (gambar 3). Amiodarone diberikan ulang sebanyak 300 $\mathrm{mg}$ intravena dan diikuti dengan dosis pemeliharaan. Angiografi pasca pemasangan stent menunjukkan tidak adanya milking effect pada segmen MB. Episode VT tidak terulang kembali (gambar 4). Amiodarone dihentikan pada hari berikutnya tanpa adanya VES

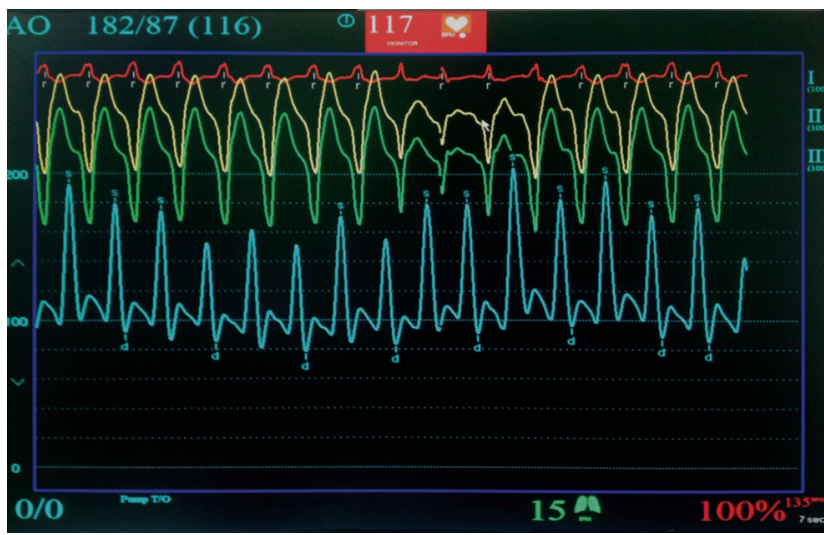

Gambar 3. Episode VT yang terekam selama prosedur PCI

semenjak prosedur PCI. Pasien dipulangkan setelah 5 hari perawatan dengan pengobatan aspirin $160 \mathrm{mg}$ dan clopidogrel $75 \mathrm{mg}$. Holter monitoring yang dilakukan 1 minggu setelah PCI tidak menunjukkan adanya ekstrasistol ataupun bentuk aritmia lainnya.

Pemeriksaan lanjutan dilakukan setiap bulan. Tidak didapatkan gejala dan pasien menunjukkan kondisi klinis yang baik. Tes treadmill yang dilakukan setelah 3 bulan menunjukkan tidak adanya iskemia dengan kapasitas latihan yang baik. Pengobatan dilanjutkan dengan evaluasi berkala terhadap kemungkinan 
timbulnya penyempitan lumen sebagai akibat dari respon proliferasi terhadap kerusakan endotel selama implantasi stent ataupun karena kerusakan kerangka stent akibat kompresi eksternal pada segmen MB.

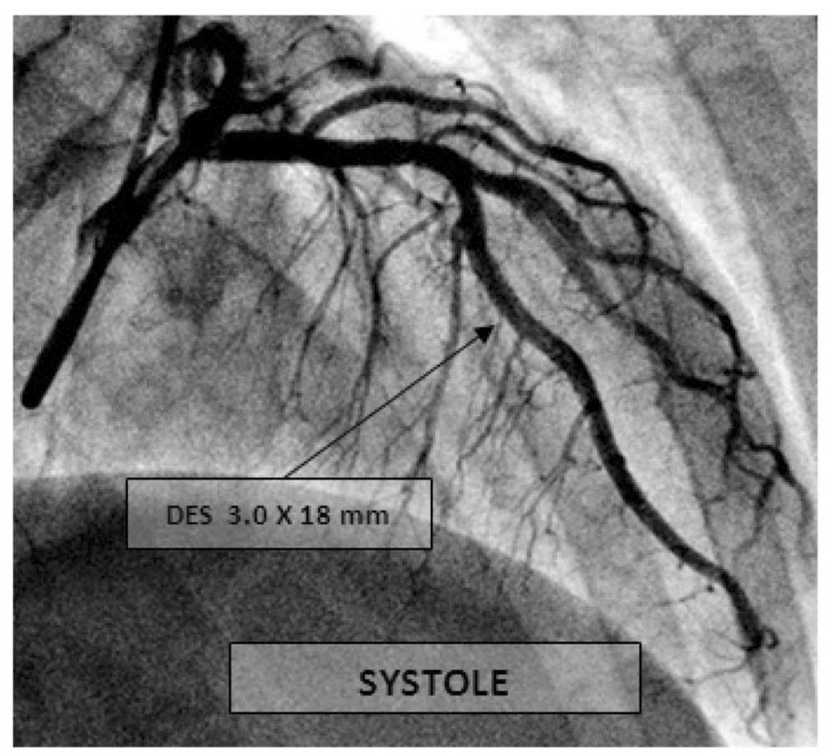

Gambar 4. Angiografi Koroner setelah pemasangan stent pada segmen MB menunjukkan patensi segmen mid-LAD dengan 1 DES pada fase sistolik.

\section{Diskusi}

Insiden $\mathrm{MB}$ bervariasi antara 5-85\% pada studi nekropsi, sementara prevalensi temuan angiografi koroner jauh lebih sedikit. Perjalanan klinis MB umumnya jinak dengan angka five year survival $97,5 \%$. Namun, iskemia miokardium, infark, aritmia, dan kematian mendadak kerap dilaporkan oleh beberapa penulis. ${ }^{4,8,9}$ Pada kasus ini, pasien menunjukkan gejala setelah perawatan sebelumnya di rumah sakit daerah yang didiagnosa dengan sindorma koroner akut, dan gejala cenderung menetap sampai pasien masuk ke rumah sakit dengan nyeri dada dan bukti adanya VES bigemini dengan episode VT non-sustained. Penyakit jantung koroner pertama kali diduga sebagai etiologi angina dan aritmia dengan adanya faktor risiko perokok berat, namun CA yang dilakukan tidak menunjukkan adanya penyakit jantung koroner melainkan ditemukan MB pada mid-LAD. Dengan demikian diagnosa MB simptomatik ditegakkan dengan perlunya intervensi segera karena tidak adanya respon terhadap terapi medikamentosa.
Kebanyakan literatur menekankan peranan CABG dan miotomi sebagai terapi terdepan $\mathrm{MB}$ yang refrakter terhadap medikamentosa. ${ }^{5}$ Namun, banyak negara berkembang akan menghadapi masalah karena tidak tersedianya fasilitas bedah jantung pada sebagian besar daerah. Risiko perforasi ventrikel kiri yang dapat terjadi sebagai komplikasi juga mempersulit didapatnya persetujuan pasien. ${ }^{14}$ Pemasangan stent diketahui merupakan alternatif untuk mengatasi masalah ini, meskipun belum ada laporan dengan skala yang besar untuk dijadikan rekomendasi yang resmi. ${ }^{13,17-19}$ Beberapa laporan diketahui menunjukkan hasil yang bervariasi mengenai keberhasilan implantasi stent koroner pada MB tanpa adanya bukti lesi atherosklerosis, namun laporan-laporan tersebut hanya memuat observasi jangka pendek. ${ }^{17-19}$ Sebuah studi oleh Klues dkk menunjukkan bahwa pemasangan stent dapat memperbaiki abnormalitas hemodinamik dan gejala, namun pemantauan jangka panjang tidak dilaporkan. ${ }^{18}$ Singh $\mathrm{H}$ dkk melaporkan implantasi DES pada segmen MB yang menyebabkan infark miokard dengan hasil yang baik setelah pemantauan selama 8 bulan. Laporan ini adalah laporan pertama yang menunjukkan keberhasilan pemasangan DES untuk MB simptomatik. ${ }^{13}$

Sebaliknya, sebuah studi oleh Kursaklioglu dkk menunjukkan angka yang cukup tinggi terjadinya instent restenosis pada pemantauan 6 bulan dalam $67 \%$ kasus, dibandingkan dengan $28 \%$ kasus pemasangan stent pada lesi atherosklerosis. ${ }^{15}$ Haager $\mathrm{dkk}$ mengevaluasi hasil pemasangan stent pada 11 pasien dengan $\mathrm{MB}$ simptomatik. ${ }^{16}$ Angiografi ulang pada minggu ke-7 menunjukkan restenosis pada $50 \%$ pasien dengan derajat yang bervariasi, dari ringan hingga berat. Revaskularisasi kemudian diulang pada 4 pasien, 2 pasien menjalankan PCI, sisanya menjalankan CABG. Hasil dari evaluasi klinis setelah 2 tahun menunjukkan temuan yang normal pada keempat pasien. Mekanisme pembentukan plak atherosklerosis yang sering ditemukan belum jelas, tetapi kontribusi injury dalam dan peregangan pembuluh darah telah ditunjukkan sebagai faktor pemicu proliferasi neo-intimal di dalam stent, bahkan pada arteri koronaria yang normal sekalipun, yang menimbulkan efek "sandwich" pada pembuluh darah yang terkompresi sehingga menginduksi proliferasi neo-intimal. ${ }^{20}$ Studi terkini oleh Li Wan dkk juga menunjukkan angka restenosis pada $50 \%$ pasien yang dilakukan implantasi stent pada segmen MB setelah 3-7 bulan. Pasien lainnya hanya mengeluhkan nyari 
dada okasional tanpa adanya perawatan ulang setelah pemantauan selama $26-48$ bulan. $^{5}$

Pada kasus ini, pemasangan stent merupakan satusatunya pilihan karena aritmia yang mengancam nyawa yang sangat mungkin disebabkan oleh $\mathrm{MB}$, karena tidak tersedianya fasilitas bedah jantung yang tersedia. DES dipilih untuk mencegah terjadinya restenosis yang diinduksi oleh proliferasi intimal, khususnya pada bagian proksimal $\mathrm{MB}$ yang rentan terhadap pembentukan atherosklerosis dan segmen lain yang terkompresi akibat adanya efek "sandwich". ${ }^{20}$ Stent dikembangkan pada tekanan $12 \mathrm{~atm}$, diatas tekanan nominal (8 atm) untuk mendapatkan tekanan adekuat yang mencapai diameter lumen yang tepat mencakup keseluruhan panjang $\mathrm{MB}$ dari segmen proksimal sampai distal dari arteri koronaria non-tunnelled. Pencegahan komplikasi implantasi stent yang berupa diseksi arteri, perforasi, abrupt vessel closure, ekspansi stent yang tidak adekuat, dan trombosis sub-akut telah menjadi panduan yang perlu untuk diperhatikan dan dipertimbangkan untuk mencapai hasil yang optimal dari pemasangan stent koroner. ${ }^{21}$

Pada kasus ini, komplikasi 2 episode VT monomorfik yang tidak stabil selama PCI diatasi dengan defibrilasi monofasik 100 Joule, yang diikuti dengan pemberian amiodarone. CA setelah implantasi stent menunjukkan tidak didapatkan lagi milking effect dengan aliran TIMI 3 ke sirkulasi distal LAD, tanpa adanya episode VT setelahnya.Meskipun banyak studi menunjukkan perlunya evaluasi ultrasonografi intravaskular untuk mengevaluasi posisi stent, pertimbangan finansial dan keterbatasan fasilitas masih menjadi masalah di kebanyakan tempat di Indonesia.

Pasien kemudian dipulangkan pada hari ke-5 perawatan setelah PCI dengan kondisi yang baik. Tidak ditemukan adanya nyeri dada ataupun palpitasi setelahnya. Pasien diberikan 2 obat antitrombotik dan edukasi untuk berhenti merokok untuk mencegah risiko timbulnya penyakit jantung koroner dan restenosis. Oleh karena tingginya insiden restenosis pada studi sebelumnya, pasien juga diberikan edukasi untuk kondisi klinisnya yang mungkin berulang. Pemeriksaan ulang dilakukan setiap minggu selama 1 bulan pertama dan setiap bulan selanjutnya. Evaluasi klinis, Holter monitoring, dan tes treadmill 3 bulan setelah PCI menunjukkan kondisi klnis yang baik dan tidak adanya gejala sisa. Mempertimbangkan risiko restenosis, pemantauan komplikasi jangka panjang harus tetap menjadi perhatian bersama pasien dan penulis. ${ }^{5}$

\section{Kesimpulan}

Telah dilaporkan pemasangan stent koroner dengan DES pada mid-LAD dengan indikasi MB simptomatik, angina berulang dan aritmia yang mengancam nyawa, yang tidak dapat diatasi dengan terapi medikamentosa. Pemantauan berkala sampai bulan ke-3 menunjukkan hasil yang baik. Namun pemantauan selanjutnya untuk mendeteksi kemungkinan penyempitan lumen pembuluh darah karena proliferasi intimal atau fraktur stent karena kompresi MB.

\section{Daftar Pustaka}

1. Chen JS and Lin CL. Myocardial bridging. Tzu Chi Med J 2003; 15(6): 357-361.

2. Dermengiu D, Vovolis I, Sorin H, Curca GC, Rusu MC, and Luca L. Morphological features in myocardial bridging. Rom J Leg Med 2010; 18: 163-170.

3. Alegria JR, Herrmann J, Holmes DR, Lerman A, Rihal CS. Myocardial bridging. European Heart Journal 2005; 26: 115968.

4. Karfis I, Dresios C, Kotsalou I, Voyatzis M, Antoniadis D, Dimakopoulos N. Myocardial bridge: An unusual cause of asymptomatic ST-elevation during treadmill stress test causing functional ischaemia. Hell J Nucl Med 2012; 15(2): 147-9.

5. Wan $\mathrm{L}$ and Wu Q. Myocardial bridge, surgery or stenting? Interactive CardioVascular and Thoracic Surgery 2004; 4: 517-20.

6. Kelle S, Thouet T, Tangcharoen T, Fleck E, and Nagel E. Anatomical and functional evaluation of myocardial bridging on the left anterior descending artery by cardiovascular magnetic resonance imaging. Journal of Cardiovascular Magnetic Resonance 2006; 8: 755-7.

7. Hayashi $\mathrm{T}$ and Ishikawa K. Myocardial bridge: Harmless or harmful. Internal Medicine 2004; 43: 1097-8.

8. Rahman A, Burma O, Uyar IS, Karaca I, Ilkay E, and Cekirdekci A. Surgical approach in symptomatic myocardial bridge. Asian Cardiovasc Thorac Ann 2000; 8: 158-60.

9. Kurt IH. A case of muscular bridge resulting in myocardial infarction following heavy effort: a case report. Cases Journal 2009; 2: 135.

10. Abhilash SP, Krishnakumar B, Velappan P, PrabhaninGupta, Viswanathan S, Koshy AG. Myocardial bridging: Clinical and angiographic profile in last 5 years; a study of 129 cases. Kerala Heart Journal Nov. 2010-Jan. 2011 : 9-13.

11. Cotlar MJ. Myocardial bridging. Journal of Insurance Medicine 2004; 36: 335-8.

12. Vuyst DD. Vanhoenacker FM, Catry F, Mespreuve M, Praeter GD. Myocardial bridging of the left anterior descending coro- 
nary artery. JBR-BTR 2009; 92: 148-9.

13. Singh H, Singh C, Kumar A, Aggarwai N, and Banerji A. Acute myocardial infarction secondary to myocardial bridge treated with drug-eluting stent. Indian Heart J 2005; 57: 734-7.

14. Zwaan D and Wellens HS. Left ventricular aneurysm subsequent to cleavage of myocardial bridging of coronary artery. J Am Coll Cardiol 1984; 3: 1345-8.

15. Kursaklioglu H, Barcin C, Iyisoy A, Kose S, Amasyali B, and Isik E. Angiographic restenosis after myocardial bridge stenting: A comparative study with direct stenting of de-novo atherosclerotic lesions. Jpn Heart J 2004; 45: 581-9.

16. Haager PK, Schwarz ER, Vom Dahl S, Klues HG, Reffelmann $\mathrm{T}$, and Hanrath P. Longterm angiographic and clinical follow up in patients with stent implantation for symptomatic myocardial bridging. Heart 2008; 84: 403-8.

17. Kurtoglu N, Mutlu B, Soydinc S, Tanalp C, Izqi A, Dagdelen S, Bakkai RB, and Dindar I. Normalization of coronary fractional flow reserve with successful intracoronary stent placement to a myocardial bridge. J Interven Cardiol 2004; 17: 33-6.

18. Klues HG, Schwarz ER, Vom Dahl J, Reffelmann T, Reul H, Potthast K, Schmitz C, Minartz J, Krebs W, and Hanrath P. Disturbed intracoronary hemodynamics in myocardial bridging. Circulation 1997; 96: 2905-13.

19. Stables RH, Knight CJ, McNeill JG, and Sigwart V. Coronary Stenting in the management of myocardial ischemia caused by muscle bridging. Br Heart J 1995; 74(1): s90-2.

20. Li W, Li Y, Sheng L, Gong Y. Myocardial bridge: Is the risk of perforation increased? Can J Cardiol 2008; 24: e80-1. 